\title{
Problemas de realismo y teoricismo en la investigación social y en el Trabajo Social
}

\author{
Estela Grassi \\ Facultad de Ciencias Sociales de la Universidad de Buenos Aires \\ (UBA)
}

\section{Problemas de realismo y teoricismo en la investigación social y en el Trabajo Social}

Resumen: Este artículo reflexiona acerca de problemas de la investigación social en el Trabajo Social. Discute la postura ingenua que lleva a suponer que la intervención profesional es inmediata 'en la realidad de los problemas'; y aquella que pone por delante una teoría como portadora del conocimiento verdadero 'sobre la realidad', como si ésta precediera a todo conocimiento. Define a la investigación como la práctica social que tiene como razón de ser producir conocimientos, al tiempo que se inscribe en, y alimenta, los procesos político-culturales de producción de problemas sociales. Por eso, para el Trabajo Social, no es equiparable al diagnóstico social, sino que debería ser un proceso continuo que acompaña el desarrollo de cualquier proyecto social y práctica profesional. Esto exige la disposición a aprender el oficio (esto es, dominio teórico, manejo metodológico-técnico y actitud de duda) y a prevenirse de los riesgos de la naturalización de los problemas para los que se reclama su intervención, que pueden provenir tanto del realismo ingenuo como del teoricismo.

Palabras clave: realismo, teoricismo, investigación, práctica social, producción de conocimiento.

\section{Problemas de realismo e teoricismo na pesquisa social e no Serviço Social}

Resumo: Este artigo reflexiona acerca de problemas da pesquisa social no Serviço Social. Discute a postura ingênua que leva a supor que a intervenção profissional é imediata na 'realidade dos problemas'; e a que antepõe uma teoria como portadora do conhecimento verdadeiro 'sobre a realidade', como se esta precedesse a todo conhecimento. Define a pesquisa como a prática social que tem como razão de ser a produção de conhecimentos, ao tempo que se inscreve nos processos político-culturais de produção de problemas sociais, e os alimenta. Por isso, para o Serviço Social, a pesquisa não é equiparável ao diagnóstico social, e sim deveria ser um processo contínuo que acompanhe o desenvolvimento de qualquer projeto social e prática profissional. Isto exige disposição para aprender o ofício (ou seja, domínio teórico, manejo metodológico-técnico e atitude de dúvida) e para prevenir-se dos riscos da naturalização dos problemas, para os quais é requerida a sua intervenção, que podem provir tanto do realismo ingênuo quanto do teoricismo.

Palavras-chave: realismo, teoricismo, pesquisa, prática social, produção de conhecimento.

\section{Problems of Realism and Theorization in Social Research and Social Work}

Abstract: This article analyzes the problems of social research in Social Work. It discusses the naive position that leads to the supposition that professional intervention is immediate 'in the reality of problems'; and that which understands that theory possesses a true knowledge 'about reality', as if this would precede all knowledge. It defines research as social practice that has as its raison d'état the production of knowledge, while it inscribes itself in and feeds the political-cultural processes of production of social problems. For this reason, for Social Work, research is not equivalent to social diagnosis, but should be a continuous process that accompanies the development of any social project and professional practice. This requires a willingness to learn the profession (theoretical command, methodological-technical management and a questioning attitude), and to protect against the risks of the naturalization of the problems in which it is required to intervene, which can be caused by either a naive realism or theorization.

Key words: realism, theorization, research, social practice, production of knowledge. 
La narración de un suceso que me ocurriera algunos pocos años atrás me da pie para presentar el tema de este artículo. El hecho es el siguiente: exponía ante los estudiantes regulares de la materia a mi cargo $^{1}$, los fundamentos de los criterios de evaluación del curso. Decía que desde mi punto de vista el paso por la universidad debe dar lugar, en primer lugar, a un 'método de pensar' que mantenga el alerta y la inquietud ante todo lo que se da por conocido acerca de 'la realidad', cualquiera sea el ámbito de donde provenga (también de nuestros propios lugares), y que esta necesaria vigilancia se debe al lugar que tiene el conocimiento social en el 'hacer la realidad' y no solamente en mostrarla. Les decía, además, que esa actitud de alerta es la mejor garantía de 'formación permanente' de los egresados y, citando a Bourdieu (1995), que ese oficio de pensar se pone de manifiesto en el modo de formular preguntas y de 'problematizar' lo que nos viene dado como los problemas verdaderos o como leyes a-históricas, bajo cualquier supuesto con que éstos y éstas sean concebidas.

Cuando explicaba que esta capacidad tiene que ver con la práctica de la investigación, y con sus reglas, un estudiante me hizo saber que su intención era 'ser trabajador social y no antropólogo'. Con su aclaración me quería decir que estas preocupaciones no corresponden a estos profesionales, sino eventualmente a los científicos sociales (en este caso, los antropólogos sociales) que deberían 'transmitirles' a los futuros trabajadores sociales, las teorías y, llegado el caso, proporcionarle los datos acerca de la realidad en la que tendrá que actuar. Es decir, que su manifestación de disconformidad expresaba la clásica suposición de que los trabajadores sociales se ocupan de "problemas concretos... de aquellos que sin lugar a dudas, afectan a la gente, no de estudiarlos'. Este hecho, que no por repetido me sorprendió menos, me llevó a reflexionar nuevamente sobre el problema que se plantea como 'la relación teoría-práctica' y a advertir que el deseo bienintencionado de actuar de manera inmediata en la resolución de problemas sociales, se sostiene en la 'creencia en la realidad ontológica del problema'.

Por cierto, más allá de la anécdota, la preocupación por la formación profesional de los trabajadores sociales y la cuestión de la implicación de su práctica con la investigación social, están hoy firmemente instalados en los debates y como preocupaciones legítimas del campo, más aún en las instituciones de enseñanza de nivel universitario, aunque no deja de estar presente en el imaginario aquella vieja conflictiva relación entre lo que parece entenderse, muchas veces, como dos universos distantes. Conflictiva que hunde sus raíces, en el caso de Argentina, en la tradición asistencial y de profesión de apoyo a la profesión médica primero ${ }^{2}$ y, más tarde, de auxiliar en las instituciones de reclusión policial ${ }^{3}$ y psiquiátri- ca, sucesivamente. De estos lugares socioinstitucionales, en los que germinó la profesión, pasaron a desarrollarse los proyectos de profesión autónoma, más cercanos a la tradición del trabajo social norteamericano ${ }^{4}$, que prontamente abrió paso al movimiento de la reconceptualización, en un momento de marcada efervescencia política en el país ${ }^{5}$. La indiferenciación de la práctica profesional y la práctica política propiamente dicha, puede explicar, en buena medida, la dificultad para trascender la crítica al tecnicismo que caracterizó a sus impulsores. La retórica ideológica en la que, como bien señala Alayón (2005), convergieron corrientes marxistas, cristianas, tercermundistas, modernizadoras, etc., fue también anti-institucional y no logró plasmar en una profesión capaz de crítica teórica reflexiva y disposición de recursos metodológicos acordes, simultáneamente.

En consecuencia, dos supuestos acerca del mundo social, aparentemente opuestos entre sí, coexisten en el campo del trabajo social, los que no son de su cosecha, pero se suelen manifestar con mayor radicalidad: una lleva a suponer que la intervención profesional es directa 'en la realidad de los problemas', para lo que son suficientes las herramientas técnicas y el conocimiento 'de cómo son las cosas...' (los problemas concretos; aún más, las personas concretas que sufren el problema). Conocimiento que estaría dado por la inmersión en tal realidad y/o reflejada por algunas categorías, índices, ${ }^{6}$ etc., (con) fundidas con lo real. El otro supuesto conduce a suponer que es posible saber cómo son las cosas porque están dichas ya en la teoría verdadera o modelo teórico (por lo que es cuestión de conocer muy bien ésta, cuanto menos contaminada por otras corrientes, mejor).

Sumado a cierto perfil 'practicista', asentado en una genuina vocación de sus agentes, pero que determina que lo primero es la acción (o 'intervenir en la realidad'), estas perspectivas obturan la inquietud por averiguar cómo son las cosas allí donde toca intervenir y cómo es que los problemas llegan a merecer algún tipo de intervención. Si el primer supuesto estructuró la formación del campo profesional, cuya razón de ser era 'hacer' acciones directas e inmediatas de asistencia o educación con la orientación de la moral, el higienismo médico, el derecho, etc. (y sus 'guías para la acción') ${ }^{7}$, o según un saber emanado de la 'inmersión en la realidad' (siguiendo el orden de aparición en la historia de la formación del campo), el teoricismo es propio de una mayor articulación a las ciencias sociales y de la adopción de algunas corrientes teóricas, particularmente del marxismo. En algún sentido, se trata de una teorización insuficiente, buena parte de ella autocentrada en el propio campo. No obstante, uno y otro constituyen modos de pensar la realidad social que trascienden al trabajo social y, como sostendré al 
final, constituyen un problema por sus implicancias y consecuencias no únicamente profesionales o teóricas, sino también políticas ${ }^{8}$.

En un artículo anterior sobre investigación en el Trabajo Social (GRASSI, 1995), sostuve y fundamenté por qué la producción de conocimientos fundados en la investigación social está implícita en la posibilidad del Trabajo Social de constituirse en un campo profesional relativamente autónomo. Efectivamente, en las últimas décadas se fueron conformando y consolidando en Argentina, núcleos importantes de formación de grado y posgrado, a pesar del contexto desalentador del pensamiento creativo durante los años del neoliberalismo, efectos que podían advertirse en la producción de las ciencias sociales en general. En ese sentido, el esfuerzo de integración a las instituciones y condiciones de producción del sistema universitario en un pie de igualdad con las disciplinas de larga tradición en la investigación, y con sus especialidades profesionales, la participación en los espacios de acreditación de proyectos de investigación, extensión y docencia de posgrado, la formación de grupos de investigación-acción o la participación en equipos multidisciplinarios, la cada vez mayor presencia de jóvenes profesionales en los posgrados, con becas del Consejo Nacional de Investigaciones Científicas y Técnicas (CONICET), o cursando residencias científicas en instituciones (en salud, principalmente), o realizando pasantías, etc., constituyen un conjunto de indicadores de lo que puede reconocerse como una nueva profesionalización que hay que destacar. Estos esfuerzos aún no son mayoritarios, pero marcan una tendencia bien definida y sientan las bases para una reubicación del Trabajo Social en el campo de las intervenciones en lo social, de la que debe tomarse debida nota, para trabajar por su consolidación ${ }^{9}$.

Siendo esto así, y en apoyo de ese proceso, no está de más llamar la atención sobre los problemas que necesariamente condicionan tal implicación, como los que acabo de mencionar, porque ambos concurren a conformar un modo de pensar y una ideología naturalizante de lo social, uno porque hace emanar la realidad de 'lo que se ve', reflejado en los términos con que se nombra; otro, porque endilga a 'la teoría' la condición de expresión exacta de un objeto real que precede a la experiencia y al conocimiento. Como ya advertí, estos no son problemas privativos del Trabajo Social (aunque se inscriban en sus reglas específicas). De hecho - y al ritmo de su propia formación - el campo disciplinar de las políticas sociales presentó problemas semejantes, aunque en este caso la 'intervención en la realidad' se reemplace por la gestión e implementación de programas como proceso meramente técnico, y el teoricismo se haya filtrado como una red conceptual que uniformó el discurso referido a estas políticas.
En síntesis, ciertos problemas del contenido conceptual y epistemológico del Trabajo Social no pueden pensarse aislados del contexto general de producción de las ideas en las materias que le son afines y de las condiciones y las formas institucionales de producción de conocimientos; más aún, de su inscripción en el proceso de producción de las interpretaciones políticas. Pero esto no da cuenta de la manera específica como lo procesa cada campo, cuestión que corresponde a su lógica y dinámica interna, en la que se comprende este acercamiento en ciernes, en parte tardío y aún parcial, si se mira más allá de los núcleos con mayor capacidad de dirección como son los centros universitarios de formación de trabadores sociales ${ }^{10}$. Si se entiende al campo profesional con el sentido del concepto bourdiano; es decir, como espacio de relaciones objetivas, estructuradas en, y estructurantes de las prácticas y esquemas de representación por medio de los cuales se reproduce la profesión; y constrictivas y habilitantes (en los términos de Giddens, 1995) de las interacciones de sus agentes, que son quienes hacen ese espacio del mundo social, corresponde desenmarañar las reglas y las formas de poder internos a la profesión. Estas últimas han reproducido hasta ahora este matrimonio malavenido con el conocimiento y la han apoltronado en el mito de la transparencia de lo real y/o en la reificación del concepto, y están al acecho (transfiguradas en discursos oscuros y de alto contenido emotivo), aunque estén en retirada.

Problematizar estas cuestiones es indispensable para avanzar en la auto-comprensión y en el autoanálisis del campo. Pero esto no es lo único que los trabajadores sociales pueden aportar a la comprensión de los procesos sociales y a la construcción - quizás de un enfoque que lo caracterice. Es esperable que los intereses de investigación del Trabajo Social conduzcan hacia la definición de problemas inmediatamente relacionados con el quehacer profesional y, en ese sentido, cercanos a la experiencia de los sujetos con los que se relaciona y referidos a las problemáticas sociales ya delimitadas o a problemas sociales aún en debate; probablemente el recorte temporal y espacial sea acotado por las necesidades institucionales y de intervención. Pero, como enseñó Bourdieu (1995), no hay objetos pequeños, sino preguntas mal formuladas y mediaciones metodológicas inexistentes o mal establecidas. Las preguntas que suscite un problema localizado y, antes aún, la definición misma del problema y el caso particular al cual el problema se refiera (el barrio, la escuela, el hospital), nunca son meramente 'locales' ni están desconectados del modo de producción de los problemas, principalmente, los problemas sociales. El caso corresponde siempre a un universo posible, al que expresa de un 
modo particular. Tampoco hay razones que limiten el campo objetual para el Trabajo Social, por lo que, en cualquier caso, lo involucran los debates generales sobre la investigación social, como a cualquier otro campo en el que ésta sea su medio de producción.

\section{La práctica de la investigación social}

Tal como afirmo en el punto anterior, el Trabajo Social no podría consolidarse como campo profesional autónomo si permaneciera ajeno, en tanto campo, de la producción para el conocimiento de aquellos procesos y problemáticas sociales en los que se halla implicada su práctica, y desde ese punto de vista le atañen los problemas de la investigación social. En lo que sigue, me refiero a ésta en tanto práctica social específica, cuya razón de ser es producir conocimientos (información confiable, interpretaciones, explicaciones), acerca de los hechos, acontecimientos y procesos sociales, y de las relaciones e interacciones entre agentes diversos, de sus instituciones, etc., que ella misma contribuye a definir como objetos relevantes, respecto de los cuales caben formularse preguntas y/o hipótesis. En tanto práctica social, tal problematización se inscribe, y alimenta, los procesos culturales de producción de problemas. De ahí que su particularidad y relevancia dependa de la capacidad de sus agentes de hacer visible esta inscripción y de problematizar (desplegar en todas sus consecuencias posibles de ser aprehendidas) tales procesos que se nos presentan a la experiencia como inmediatamente "reales'. Es decir (para entendernos en lo que sigue), entiendo que es vano el esfuerzo (más aún, contraproducente) por hallar la 'verdad verdadera' detrás de cualquier manto (la ideología, las creencias, la ignorancia), por dos razones: porque se procede por el único medio del que dispone la totalidad de los agentes humanos, cual es el lenguaje, y el lenguaje teórico y técnico es una mediación, pero no un puente de plata; y porque tal información, explicaciones, problemas, etc., son parte de los susodichos procesos culturales de producción de problemas. Desde este punto de vista, no hay ajenidad ni distancia, lo que no habilita la indiscriminación, sino una objetivación más reflexiva. Esto desestima algunas expectativas erróneas y ciertos posicionamientos básicamente interesados, que acompañan a la práctica de la investigación en general, más cuando se asocia a la intervención o la gestión (caso de la investigación en Trabajo Social y en política social).

La primera advertencia refiere a qué es posible esperar de la investigación (para la intervención, para la gestión, para la definición de políticas, etc.), porque dando por hecho que éstas no pueden estar libradas al tino o al capricho de los funcionarios (sea cual fuere el nivel de la estructura institucional que ocupen), tampoco cabe hallar en la investigación una panacea que, al especificar las variables y dar la magnitud justa de un problema, por derivación, va a permitir tomar las medidas definitivamente adecuadas para su solución ${ }^{11}$. El conocimiento, su producción, los modos y condiciones de esa producción y los resultados de la investigación, no escapan (es más, se inscriben necesariamente), en los procesos de hegemonización; en la disputa por la imposición de las visiones legítimas de cómo son las cosas, de la estructuración de la percepción del mundo social; en consecuencia, en la lucha por la estructuración del mundo social. Producir conocimiento no es solamente un 'hacer ver objetivo': la información es generalmente reapropiada con significados diversos, y los conceptos circulan en contextos discursivos a veces contrapuestos. Pero además, en la dinámica de la vida social y política, un problema no se cierra sin más ${ }^{12}$, sino que cada movimiento - incluso cada progreso en un área cualquiera -, abre nuevas dinámicas (demandas, frentes de conflicto, etc.) que ni la más comprehensiva de las propuestas puede prever en su totalidad ${ }^{13}$.

La segunda advertencia se refiere a las actitudes ante esta práctica: investigar no es hacer o dominar una ciencia oculta, ni es para iluminados, de modo que su quehacer está al alcance de quien se decida a aprender el oficio; pero tampoco es una chapucería que se improvisa de cualquier modo y se resuelve con una lista de preguntas para después contar cuántos entrevistados respondieron por sí y cuántos por no, o con observaciones y comentarios previsibles, manifestaciones de compromiso, citas intrascendentes, referencias técnicas rebuscadas para nombrar procedimientos corrientes que, como no se describen, pueden parecer sofisticados, etc. El proceso y método (cualquiera sea) que siga una investigación (otra vez, como enseña Bourdieu, 1995) no se corresponde a la receta de cocina: no basta tener los ingredientes en las medidas justas (la muestra representativa o cualitativa, 
el emergente observable) ${ }^{14}$; una buena batería de cocina (el programa estadístico SPSS); hacer una buena mezcla, en las proporciones correspondientes de cuánto y de qué cualidad (triangulación, análisis multivariado) y ya... la torta sale en su justo punto (la realidad tal como la muestran los datos 'reales'). El manejo metodológicotécnico es indispensable pero no suficiente, en principio, para formular un problema con los problemas que ya vienen dados, y luego porque los procedimientos técnicos operan con información que el investigador fue capaz de construir como datos significativos del problema. La investigación no es, ni mucho menos, para iluminados, pero requiere disposición a aprender el oficio; y un estado de curiosidad, de inquietud y de insatisfacción permanente ante lo que se instala como 'respuesta', como 'sabido', y sobre todo, como un problema obvio, para el que se reclama la intervención de profesionales. Una combinación (disposición, manejo metodológico-técnico y capacidad de duda) cuyo óptimo es, sobre todo, una meta, no un estado que se alcance para nuestra seguridad y tranquilidad con lo que hacemos.

La investigación es el recurso de las disciplinas del campo social que permite interpretar y formular explicaciones posibles de los hechos, acontecimientos y procesos sociales. Comprende la dimensión e incidencia que tienen, como el contexto de su ocurrencia, el sentido o la dirección que toman los procesos, y la trama de las relaciones que no se dan a simple vista, pero sí en las prácticas e interacciones sociales en las que se reproducen. Para las prácticas de las profesiones de lo social es, además, el medio para definir objetivos, metas, acciones y recursos, para prever consecuencias de estas intervenciones, articular estas definiciones a las estrategias de los agentes involucrados, adecuar la marcha de los proyectos o programas, corregir equivocaciones o imprevistos, etc., sabiendo, al mismo tiempo, que todas estas decisiones y previsiones se inscriben, inmediata o indirectamente, en la disputa por la orientación de los procesos históricos (es decir, por conducir hacia determinados resultados, lo que quiere decir que algún tipo de compromiso es ineludible). Por su parte, la 'investigación con participación' de los sujetos involucrados en un proyecto o plan social, comparte exactamente estas mismas condiciones, y exige del profesional-investigador, mayor experiencia y oficio, y máxima vigilancia de su práctica, para problematizar las definiciones preconstruidas, que se hallan inscriptas en los procesos culturales a los que aludí antes, así como en la particularidad de la comunidad o grupo involucrado en el proyecto.

Los trabajadores sociales, igual que los demás agentes del campo de las políticas sociales, necesitan sopesar y evaluar las consecuencias posibles de las intervenciones que se proponen. Sin embargo, desde la perspectiva que guía estas afirmaciones, la investigación social aún en estos campos, no es equiparable al 'diagnóstico social', en el sentido clásico de detección de causas y aplicación de 'remedios', para enderezar una anormalidad, porque las situaciones sociales son por definición, normales, aunque no sean ni buenas ni deseables. Tampoco son componentes esenciales de alguna cultura (como a veces parece decirse), sino el resultado (y contexto de reproducción) de prácticas sociales de agentes también portadores de interpretaciones de los hechos en cuestión. En ese sentido, la investigación, más que un diagnóstico que da un control definitivo de los hechos, es (debería ser) un proceso continuo que acompaña el desarrollo de cualquier proyecto social y práctica profesional.

\section{La naturalización de lo social}

Es relativamente fácil estar de acuerdo (al menos en la retórica epistemológica) en que el mundo social es diferente del mundo físico-natural y que los criterios metodológicos difieren en cada caso. Hay más coincidencias retóricas que disidencias, en la crítica al objetivismo positivista, sobre todo porque esta corriente es asociada a posiciones conservadoras y elitistas en el campo de la ciencia. Sin embargo, el modo naturalista de pensar se presenta insensiblemente en la práctica investigativa. Enumeré al principio dos presupuestos arraigados en el sentido común acerca de lo que proporciona o de lo que es posible esperar de los investigadores sociales: un conjunto de información acerca de cómo son las cosas; o una teoría verdadera que contiene de una vez para siempre, cuáles son los mecanismos o las leyes del funcionamiento del mundo social, y que, al proporcionar esas respuestas, permitiría ajustar los comportamientos a esas leyes (del mercado o del cambio histórico) al modo como, se supone, sucede con el mundo físico-natural: cuanto mejor se conoce, más se puede avanzar en el dominio tecnológico del mismo o en su control y dirección.

1. La primera de esas expectativas se asocia a otra: creer que la realidad se presenta a la vista, sea en los 'datos duros' (aquellos que se pueden expresar en índices, fórmulas o dimensiones), sea en las observaciones y vivencias del investigador en el terreno, o en las opiniones (la puesta en palabras) que expresarían las representaciones de los sujetos y que son 'recogidas' por el investigador.

Algunos estudios que se pusieron muy a la moda cuando se amplió la población que vive en condiciones de mayor deprivación, dejaban ver estos problemas. Tras el objetivo loable de captar y comprender la diversidad de situaciones a que este proceso daba lugar, en no pocas monografías, tesis e informes los conceptos producidos para dar cuenta de ellas 
(fragmentación, heterogeneidad, exclusión, pobreza), aparecían convertidos en compartimentos que permitían contar y clasificar individuos o familias (las unidades de estudio), según determinadas características variables y combinables (casi siempre, carencias) que los hacían ubicables en alguno de los casilleros clasificatorios. Con esa tónica se produjeron innumerables informes técnicos y académicos, monografías, tesis y textos del estilo que se quiera, en los que términos como 'nueva pobreza', 'pobreza estructural', 'exclusión”, 'desafiliación', parecían adquirir autonomía, pre-existir al significado, constituirse en un sistema de clasificación que a lo sumo podía perfeccionarse para asignar con máxima eficiencias los recursos escasos de los planes sociales. Es obvio (hay que afirmarlo con el mayor énfasis) que una buena descripción de la población es insoslayable en cualquier plan o política; operar sin un buen sistema de información corresponde a la falta de profesionalidad o a un practicismo ingenuo que no resiste ninguna observación. Lo que busco expresar es que esa descripción no es un reflejo de la 'realidad', o de nichos sociales, sino modos de ordenar la realidad que tanto depende de las variables que se seleccionen, de las hipótesis explícitas y las implícitas referidas a los problemas sociales que se encaran, como de la relación de todo esto con los objetivos generales de la política, que en última instancia han de determinar la información necesaria referida a la población. Lo problemático, y lo que tiene consecuencias en la disputa (política) por la representación del mundo social, es la naturalización de las clasificaciones y de los atributos que le sirven de variables, porque en ese movimiento se pierde de vista el proceso socio-histórico y las relaciones por las cuales los diferentes grupos se distribuyen de manera diferencial y desigual en el espacio social, así como las carencias y las cualidades, los recursos de la política y las responsabilidades por los problemas. Cuando esto se pierde de vista, el relevamiento de las carencias deviene confirmatorio de las estructuras, y las categorías que designan grupos de población entran al discurso técnico-político como si constituyeran grupos sociales espontáneamente delimitados ${ }^{15}$.

Desde otra perspectiva, otros estudios también a la moda, fueron aquellos que, pretendiendo hacer la crítica a los planes y programas elaborados al margen de cualquier participación de las comunidades y grupos involucrados, fueron a la búsqueda de las 'representaciones sociales'. Innumerables estudios cualitativos dirigidos a relevar el 'punto de vista de los destinatarios' de los planes sociales, se limitaron a recoger opiniones bajo el supuesto de que ellas reflejaban las cosas como son, o el radical punto de vista de quien emite la opinión (un actor concebido fuera de la lucha y las disputas por el sentido de "las cosas'), antes que como expresión del punto de mira que ofrece el lugar en una relación social y, por lo tan- to, constitutivo de la relación, no emergente de una mente individual ni sobredeterminado por un lugar 'cuasi' físico. Por ejemplo, esta limitación se advierte en algunas evaluaciones sobre impacto de programas sociales, para los que la opinión de los usuarios es tomada en sí misma como prueba de los resultados del programa. En otros casos, la 'investigación' es una evaluación crítica anticipada y es evidente la disposición del investigador a 'demostrar' cuan mal funciona un programa, a confirmar las consecuencias negativas de su implementación, y a encontrar prácticas clientelares a toda costa. Nuevamente, estoy marcando un problema de la práctica investigativa, pero no desmereciendo la fundamental importancia de contar con estudios capaces de comprender los significados que se elaboran, el carácter de las relaciones que se producen, los conflictos, divisiones, etc., a que da lugar el desarrollo de una política, más aún, aquellas focalizadas en comunidades o grupos de población localizados.

En el primer caso, el riesgo es constituir a los sujetos (mucho más aún), a los individuos y familias (unidad de análisis), en el objeto de la investigación, olvidando que 'lo social' es, como mínimo, distinto de una suma de unidades. Los 'hechos observados' (las condiciones de vida que se expresan en indicadores sociales, los puntos de vista que expresan las personas), se inscriben en las prácticas y en las relaciones de las que personas, familias y grupos participan, no como objetos, sino como agentes implicados. Para el caso de las representaciones confundidas con opiniones o como objeto ideacional disociado de la práctica social y ajeno a las relaciones, se desconoce, además, que los esquemas de representación social corresponden a la disputa por la representación, que es por la constitución y reproducción de un espacio social común, aunque en él se ocupen lugares diferentes. Enumeración de carencias u opiniones, tomadas como prueba y no como el material de un objeto complejo y multideterminado que en el proceso investigativo se buscará reconstruir, conducen a esos informes cuyas conclusiones se parecen demasiado a las respuestas que ya tenía el investigador, o que están plagados de conclusiones obvias.

Desocupación, exclusión, pobreza, pueden ser nociones con alguna capacidad descriptiva y/o potencial heurístico, si las entendemos como aquello que pretenden expresar: relaciones sociales e históricas que se realizan en formaciones particulares y según múltiples determinaciones que es necesario desentrañar cada vez. No describen un estado coyuntural de cosas, pero tampoco son invariantes históricas sobre las que no hay nada particular que conocer. Si su utilización no contribuye a describir la complejidad de la trama en la que están implicados, también, sujetos distantes en el espacio social ${ }^{16}$, los conceptos pierden sustancia y reducen los hechos y procesos sociales a la suma de rasgos de sujetos sin relación ${ }^{17}$. 
Pensar en términos sociales es pensar en términos de las relaciones y de la multiplicidad de dispositivos que convergen (y no necesariamente como un plan elaborado) en la construcción de un estado de cosas o en la producción de un problema digno de atención o de intervención ${ }^{18}$. Estudiar la pobreza requiere más trabajo que contar 'víctimas' y describir sus carencias; incluso es necesario hacer objetivo el modo de conocer y atender a la conversión de los problemas sociales en problemas particulares de quienes los padecen o consecuencia de unos rasgos de comportamiento esencialmente particulares, lo que debe mucho al trabajo intelectual, político y cultural de desocialización de lo social.

Precisamente, lo que dejaron de lado los estudios que se limitaron a enumerar rasgos o carencias de las personas, es ese trabajo intelectual de construcción del problema social (de la pobreza, de la violencia, de la educación degradada, etc.) como problema de los grupos constituidos por el despojo de recursos socialmente valo$\operatorname{rados}^{19}$; o constituidos ellos mismos como problema, al que esa misma formulación contribuía. Cuando el criterio de construcción del problema es ese, la 'solución' lógica que se desprende, es 'operar sobre' quienes tienen el problema o son un problema (educándolos, capacitándolos, empoderándolos... para incluirlos) y no sobre las condiciones y sistemas que producen una educación inapropiada, la pérdida o inadecuación de las capacidades, que obstaculizan la participación y la toma de decisiones autónomas, etc. Son tan pobres los resultados - desde el punto de vista de la superación del problema que pretenden superar - de las políticas sociales encaminadas a 'operar sobre los sujetos' (aunque la retórica diga 'con'), como la producción investigativa incapaz de construir un problema con los problemas sociales y las respectivas políticas ${ }^{20}$.

El método de las tipologías es el de las ciencias naturales; pero en esta forma de naturalismo clasificatorio hay más que un problema metodológico o epistemológico, porque lo que hay (conciente o inconcientemente) es una forma de complicidad con una determinada representación del mundo social; es decir, con una determinada estructuración del mundo social, ya que su representación "entraña un acto de construcción", como señala Bourdieu (1990) $\mathrm{o}$, al menos, una forma de participación en la lucha por su estructuración.
2. El teoricismo, por su parte, es la confusión de las formulaciones teóricas con la realidad, que lleva a buscar (y hallar) en ellas, todas las respuestas posibles para todas las situaciones, hechos, comportamientos o cambios sociales. En estos casos, las investigaciones se gastan en el esfuerzo por ajustar los datos a las especulaciones y tesis acerca de las determinantes históricas y de los comportamientos, por lo que no arrojan luz a la comprensión de las situaciones, hechos y procesos sociales concretos. Tienen poco trabajo de indagación empírica y la que hay, está al servicio de los presupuestos generales subyacentes: las leyes de autorregulación del mercado ${ }^{21}$ o las de la evolución social en cualquiera de sus versiones: la globalización, las crisis de diferente signo, la modernización, la lucha de clases, suelen 'aplicarse' a procesos y contextos cuya particularidad se pierde o sobre la que no se indaga. Si para aquel realismo el individuo se reifica hasta devenir en el problema, en este caso, los agentes desaparecen por completo y son los sistemas o instituciones los que adquieren vida y capacidad de decisión: el Estado, el mercado, el capitalismo, el neoliberalismo, el poder, etc., adquieren la condición de un Sujeto omnipresente y en cuya voluntad absoluta se halla la razón de todo acontecimiento, aún los más nimios de la vida de las personas, de una institución, de un barrio, etc. ${ }^{22}$. El apego ortodoxo al concepto o a la teoría es un obstáculo en sí mismo; y la apelación a las formulaciones más abstractas para encontrar respuestas directas e inmediatas a todos los acontecimientos y a todos los niveles de la vida social cancela y obtura el conocimiento y la comprensión de los hechos, y no pocas veces paraliza la acción reflexiva. El teoricismo es anti-teórico por definición, porque deviene ortodoxia, porque al reificar el concepto, obstruye la reflexión teórica, sin la cual no hay preguntas posibles de investigación.

\section{Investigación y producción del mundo social}

1. La particularidad del objeto de la ciencia social no estriba sólo en su naturaleza diferente respecto de aquello que estudian las ciencias naturales, por ser obra de la acción humana sino además, como adelanté en el punto anterior, por el tipo de relación de las interpretaciones que éstas producen, con su objeto (prácticas sociales). Charles Taylor (1985) señala que 
el conocimiento del universo o de la vida natural puede conducir al descubrimiento o al hallazgo de formas o mecanismos cuya existencia es relativamente independiente de la ignorancia que al respecto demuestre el sujeto, o de sus creencias acerca de cómo se producen los fenómenos naturales ${ }^{23}$. Pero el conocimiento producido acerca del mundo social (como las creencias o las ideologías) está referido a un objeto cuya existencia es inseparable de las creencias, ideologías y conocimientos que lo hacen existir. Y que, a su vez, habilita problemas y preguntas cuyas respuestas se integran a esa existencia ${ }^{24}$ como autocomprensión, sea que ratifiquen, o en competencia y en disputa con los previos conocimientos y saberes corrientes. En realidad, retorna o se hace parte del proceso de construcción de la realidad, así como de su propio objeto, al ser parte de los esquemas de representación y percepción estructurados, que son estructurantes de la práctica social, y de los modos de describirla. Tomando como referencia y ejemplo el campo del Trabajo Social, podemos ver que los estudios (investigaciones, proposiciones teóricas y de metodologías de intervención) que tuvieron (o tienen) al Trabajo Social como objeto, no devolvieron un retrato del campo sin más, el que permitiría, por eso, mayor eficacia en la acción, sino que inmediatamente formaron parte de las disputas por qué es o cómo debe ser el Trabajo Social, por su quehacer, por su lugar como profesión, por la definición de su objeto, etc. Cada movimiento de auto-análisis de la profesión, de reconceptualización de sus objetivos y métodos, o de sus sustentos teóricos, transformaron al trabajo social y abrieron nuevos problemas; lo que no quiere decir que esa transformación sea el resultado unívoco de un programa cumplido en una dirección determinada. El Trabajo Social que hoy existe, es un complejo entramado con los hilos de la vieja asistencia, del proyecto profesionalista de los años 1960, de las reconceptualizaciones posteriores, de las crisis y de las críticas varias. Se ve, así, que su formación y desarrollo como profesión de lo social no responde a un esquema necesario de evolución, común a cualquier contexto regional o país, sino que es siempre particular en su generalidad como profesión. El campo no salió indemne, para bien o para mal, de cada una de esas autorreflexiones según, además, como hayan ocurrido éstas en los contextos político-sociales locales ${ }^{25}$.

Como destacan Boltanski y Chiapello (2002) en su crítica a la naturalización del mundo en red por parte de las teorías de las redes, "el estado de las cosas y los modos de descripción no pueden tratarse independientemente de las posiciones normativas desde las que puede enunciarse un juicio de valor sobre los acontecimientos que se producen".

Esta particular imbricación de lo que la investigación social produce, con su propio objeto, es la condición que impone la mayor exigencia y autorreflexión ante el problema y las preguntas de investigación. Fue precisamente una participación escasamente reflexiva de las ciencias sociales (en general) lo que facilitó la hegemonía de un modo de pensar que establece relaciones directas y unidireccionales entre los problemas, las causas y las soluciones políticas que se implementaron, principalmente en la última década del siglo pasado. Los mismos términos circulaban en un lado y otro de los discursos, sin que se pusiera en discusión sus efectos y contenidos ${ }^{26}$.

Si un rasgo dominó entonces el panorama de la producción en materia de asuntos sociales (y, en particular, la crítica a las políticas sociales), fue la simplicidad, la linealidad de las explicaciones que establecían relaciones inmediatas de causa-efecto, la suposición de que la realidad es transparente aunada, sin embargo, a un teoricismo ciego a los procesos reales que su práctica desataba. Y la réplica (escasa) fue, muchas veces, igual de lineal, simplista y naturalista. Lo que se llamó el pensamiento único fue mucho más que el paradigma ideológico neoliberal, porque se acopló a un modo de pensar y pudo, así, cooptar la crítica a las políticas y reapropiarse de cada concepto producido en la búsqueda de dar cuenta de las consecuencias de las políticas por él orientadas, vaciándolos de contenido. Quizá el más paradigmático vaciamiento fue el de la noción de 'exclusión social', traducida rápidamente al individualismo metodológico que permitió 'contar excluidos', además de 'pobres', o sumarle a los 'pobres' otro rasgo para ubicarlos en algún casillero. Esta es, hoy, una de esas nociones que, junto con su contraparte, la 'inclusión' (y las políticas para la inclusión), requieren atravesar la prueba de unas preguntas de investigación que incluyan 'las teorías de la exclusión' que subyacen a los discursos políti$\cos ^{27}$ por los que los términos circulan con naturalidad.

2. En síntesis, para el practicismo no hay muchas preguntas que formular (o no hay tiempo para ello), porque primero está el compromiso con la realidad que se ve y que contiene o llevará 'naturalmente' a su 
conocimiento; para el empirismo, porque realidad y concepto se (con) funden, y para el teoricismo porque se dispone del modelo teórico verdadero que contiene anticipadamente las respuestas. Los riesgos son parecidos: tomar como problema el problema instalado en el debate social y político, o definido en la teoría, obstruir la comprensión de los procesos que dan lugar a esos problemas y a esas definiciones, y limitar o desestimar la producción de información confiable, la reflexión situada y el cuidadoso dimensionamiento de las problemáticas que son objeto de intervención invalidando, así, la posibilidad de dar fundamentos, información, recursos metodológicos, etc., a la práctica profesional o a la proposición de políticas.

Por cierto, la dinámica del campo del Trabajo Social, en particular en sus centros de formación, parece indicar que aquella aproximación ingenua a 'los problemas de la intervención' se encuentra en retroceso y que está clara su implicación con la investigación de las problemáticas sociales que son el objeto de su práctica. Sin embargo, dada su imbricación con la política social y la producción en esta materia, también los hechos parecen indicar la necesidad de mantener el alerta sobre las consecuencias de lo producido en las investigaciones, porque además de los datos que caracterizan y dimensionan el problema, es necesario comprender la génesis de su construcción como problema social y de intervención, para describir adecuadamente el problema y actuar reflexivamente.

\section{Referencias}

ALAYÓN, N. El movimiento de Reconceptualización. Una mirada crítica. En: (Org.). Trabajo Social latinoamericano. A 40 años de la Reconceptualización. Buenos Aires: Espacio Editorial, 2005.

. Hacia la historia del Trabajo Social en la Argentina. Lima, Perú: CELATS Ediciones, 1980.

ANDER EGG, E. Metodología y práctica del desarrollo de la comunidad. Buenos Aires: Editorial Hvmanitas, 1965.

BOLTANSKI, L.; CHIAPELLO, È. El nuevo espíritu del capitalismo. Madrid: Akal Ediciones, 2002.

BOURDIEU, P. Espacio social y génesis de las clases. En: . Sociología y cultura. Mexico: Grijalbo, 1990.

Una duda radical. En: BOURDIEU, P.; WACQUANT, L. J. D. Respuestas. Por una antropología reflexiva. Barcelona: Grijalbo, 1995.

GRASSI, E. Política y problemas sociales en la sociedad neoliberal. La otra década infame I. Buenos Aires: Espacio Editorial, 2003.
La implicancia de la investigación social en la práctica del Trabajo Social. En: Revista Margen, Buenos Aires, año IV, n. 9, p. 54-79, 1995.

GIDDENS, A. La constitución de la sociedad. Bases para la teoría de la estructuración. Buenos Aires: Amorrortu Editores, 1995.

KISNERMAN, N. Servicio Social de grupo. Buenos Aires: Editorial Hvmanitas, 1969/1971.

RAGGIO, L. De las necesidades básicas a la construcción de autonomía. Tesis (Maestría en Administración Pública) Facultad de Ciencias Económicas, Universidad de Buenos Aires, Argentina, 2005.

RODRÍGUEZ, G. Principios generales de asistencia social. Buenos Aires: Editorial Universitaria, 1960.

TAYLOR, C. La teoría social como práctica. Traducción de José Fernando García del cap. 3 de Philosophy and Social Sciencse. Cambridge University Press, 1985.

TRAVI, V. La dimensión técnico-instrumental en Trabajo Social. Buenos Aires: Espacio Editorial, 2005.

\section{Notas}

1 Antropología Social, en la carrera de Trabajo Social de la Universidad de Buenos Aires.

2 Los primeros cursos fueron de Visitadoras de Higiene Social, y seimplementaronen 1924, en laFacultaddeCiencias Médicas de la Universidad de Buenos Aires (ALAYÓN, 1980).

3 En el mismo autor, véase la historia de la Escuela de la Facultad de Derecho de la UBA y su relación con el Patronato de Liberadas. De hecho, en esta Universidad existieron simultáneamente dos carreras, una en esa Facultad y otra, en la de Medicina (que prolongó la de Visitadoras de Higiene hasta avanzados los 80). Más tarde, el discurso psicoanalítico, las corrientes de la psicología sistémica y la psicología social de Pichon Rivière tendrían marcada influencia en la profesión, particularmente en Buenos Aires. Es notable toparse aún hoy con informes de asistentes sociales en los que, tanto el problema como el lenguaje están determinados por la psicología. En algunos de esos informes son los 'deseos de los sujetos' individuales el objeto de interpretación de los asistentes sociales, que no parecen poder aportar otros elementos a la definición de los problemas en las instituciones en las que trabajan.

4 En esta línea puede inscribirse el Instituto de Servicio Social creado con la asistencia técnica de las Naciones Unidas, en 1959(ALAYÓN, 1980). 
5 Impulsada inicialmente por quienes se llamaron a sí mismos la 'generación del ' 65', y crearon luego la editorial ECRO.

6 Últimamente, excluidos, por ejemplo.

7 No deja de ser interesante observar que, si bien en los planes de estudio se incluyeron "los métodos de caso, grupo y comunidad", entre los manuales producidos por autores locales hay poco acerca del "método de caso". Los manuales más antiguos se orientan más bien hacia la educación y moralización de las familias (RODRÍGUEZ, 1960). Encambio, los manuales más conocidos y que trascendieron, son los de desarrollo de la comunidad (por ejemplo, Ezequiel Ander Egg, 1965), o sobre el método de grupo (KISNERMAN, 1969/1971). En ese sentido, la retórica crítica al método de caso, centrada en Mary Richmond, podría interpretarse mejor como expresión simbólica de la ruptura y la lucha dentro del campo, que la crítica a un método realmente existente. Aunque la citan, los higienistas locales parecen mucho más preocupados por los problemas morales que sociales $(\mathrm{o}, \mathrm{al}$ menos, construían los problemas sociales en términos morales). Viviana Travi (2005) rescata la obra de la norteamericana y discute con sus críticos.

8 En el sentido comprensivo del término, que refiere a las relaciones de poder en un orden social y a la producción de sus sentidos, fundamentos y justificaciones

9 Y es así, aunque en parte hayan sido estimulados por las exigencias de evaluaciones de la producción académica y de posgraduación para la carrera docente, establecidas recién en los últimos quince años, y sean los efectos de reglas formales externas a su campo específico. Los sucesivos golpes de Estado en la Argentina (en particular, la dictadura del período 1976-83) y las luchas internas del peronismo de los 70, han tenido efectos nefastos en la Universidad. Como consecuencia, el desarrollo de la carrera docente, de los posgrados y de los sistemas de evaluación de la producción académica y en investigación, fueron tardíos, y se dieron en el marco de las reformas políticas neoliberales y de las luchas político-partidarias que cooptaron la política universitaria, particularmente en las Universidades más antiguas. De ahí las disputas por los significados de esos sistemas, e incluso la resistencia de muchos sectores. Aún está pendiente una crítica reflexiva de lo desarrollado hasta ahora, que permita apuntalar la producción en investigación y su mayor calidad.

10 Hay que destacar la proliferación de Escuelas de Servicio Social de nivel terciario no universitario, la mayoría de ellas aisladas y con escasísima producción y sistematización de las experiencias profesionales.

11 Si esta expectativa tuviera algún viso de verdad, habría que concluir que se investigó siempre muy mal, porque de lo contrario no deberían existir más problemas sociales en el mundo. De hecho, hay estudios muy serios y bien fundados sobre casi todos los problemas sociales que, sin embargo, no se plasman en políticas, o que, aún cuando hayan dado lugar a políticas no necesariamente los problemas desaparecen, o mayormente, se abren nuevas fuentes de conflicto y nuevos problemas.

12 Esta era una aspiración de los neoliberales reformistas argentinos, implícita en la metáfora médica 'operar sin anestesia', refiriéndose a la toma de decisiones drásticas en materia de ajustes estructurales.

13 Nuevamente una aclaración: sí se pueden anticipar consecuencias posibles de lo que se hace, como de lo que se deja de hacer, tal como una parte de la producción de las ciencias sociales y económicas anticipó respecto de las consecuencias de las políticas neoliberales en América Latina.

14 Puede agregarse la Matriz del Marco Lógico, para la planificación de proyectos sociales.

15 Estas construcciones conceptuales acerca de los pobres como carecientes, son tratadas por mí en el libro Políticas y problemas sociales (GRASSI, 2003).

16 Los lugares de la no pobreza, las estrategias de gestión del trabajo, las consecuencias - también aquellas no buscadas - de múltiples acciones y decisiones de una diversidad de agentes y sus combinatorias, etc.

17 Algunos ejemplos pueden contribuir a aclarar el problema: la referencia al 'trabajador' de un modo deshistorizado o, en su defecto, esencialista. En el primer caso, el término se incorpora de un modo que pierde toda conexión con la relación en la que se hace posible la existencia y reconocimiento de un tal sujeto. Dicha relación no puede quedar disuelta tras cada hombre o mujer contado como trabajador/a, aunque cada uno de ellos la expresa de manera particular y de la única manera como pueden manifestarse las relaciones sociales. Ocupados o desocupados no son, apenas, términos que clasifican sujetos en determinada situación respecto del empleo, porque el empleo no es una forma natural de participación social, sino una institución histórica, y, en conjunto, expresan la normalización de un modo de empleo del trabajo y de organización de la población. Ala inversa, el esencialismo hace derivar de esa relación un sujeto colectivo casi tangible (la clase), cuya existencia sería anterior a su representación y a las luchas por su representación. La observación no quiere decir que es necesario reeditar estas cuestiones cada vez que se investiga sobre temas de empleo, etc., sino que las referencias son tácitas y de ellas depende el modo de construir el problema.

18 Nuevamente un ejemplo puede ser ilustrativo: la 'maternidad adolescente' devinoen un problema social que atrae la atención de funcionarios de salud, educadores, médicos, trabajadores sociales, etc., y que está fuertemente definido por el cruce de edad y primer embarazo, como el dato que determina el problema. Los médicos suelen enumerar, incluso, riesgos para 
la madre y el bebé. Sin embargo, la misma edad que ahora es 'peligrosa para parir', hasta hace pocas décadas era problemática para permanecer soltera y sin hijos. En relativamente corto tiempo convergieron un conjunto de circunstancias que dieron lugar al problema de maternidad adolescente allí donde había un problema de soltería. La lucha feminista por la igualdad de las mujeres y la liberación de la imposición de un único rol para ellas (esposa y madre), la liberalización de las costumbres, la difusión de los métodos anticonceptivos, su mayor escolarización y la reincorporación al mercado de trabajo, y las consiguientes disputas ideológicas y políticas por el control del cuerpo, de los comportamientos reproductivos y de la moral, confluyeron paraalentarposiciones normativas desde las que se puede formular un juicio acerca de la maternidad a edades tempranas y coincidir en que no es deseable. Además, se hizo más extenso el período de tránsito (más que de pasaje) haciala adultez, mientras que las funciones biológicas ya desarrolladas hacen posible el embarazo y el parto en un sujeto no maduro para asumir las funciones sociales maternales propias del adulto. En ese cruce, el embarazo puede ser conceptuado como un problema. Por último hay que considerar el efecto de normalización de la propia problematización, al tomarcomonatural y universal el problema, y hacerlo extensivo aún en contextos donde las condiciones que le dan ese sentido controvertible no se cumplen pues, a la inversa, las mujeres hallan en la maternidad un proyecto de vida(RAGGIO, 2005). Estono desestimala deseabilidad de la prórroga de la maternidad y la ampliación del horizonte de vida de las mujeres: únicamente hace conciente el sustrato de intereses en la definición del problemay le devuelve su historia.

19 Así como la construcción de la valoración de esos recursos.

20 Llevado al extremo, si el problema es el sujeto del problema, también la solución puede ser su eliminación, de lo que dan prueba las erradicaciones que encaraba la última dictadura, como solución al problema de la vivienda y de la infraestructura urbana.

21 Un ejemplo típico fueron las interpretaciones que hacían los economistas neoclásicos acerca de la incorporación de empleados no registrados: afirmaban que se trataba de los ajustes automáticos del mercado frente a las rigideces de las leyes laborales. En la lucha política, esta interpretación era una forma de abogar por la derogación de las protecciones al trabajo, por parte de actores concretos.

22 Con signo positivo o negativo, los términos 'globalización', 'mundialización', 'posmodernidad', 'ajuste', por citar algunos, se hicieron presentes como caballitos de batalla en innumerables monografías e informes de investigación, en buena parte de ellos innecesariamente, y en otra, aludidos como fenómenos cuya ocurrencia escapaba a toda voluntad.

23 Por cierto, la tierra giraba alrededor del sol antes y después de Galileo, aunque ese descubrimiento condujo a ampliar el control del universo hasta los viajes espaciales del último siglo. Sin embargo, cada vez más los avances en estas ciencias (de la que es más expresiva la genética) ponen en duda la radical separación sujeto-objeto.

24 Boltanski y Chiapello (2002) señalan que fue necesario que el mercado estuviese ubicado en el centro de la filosofía política, a finales del Siglo 18, para que las dimensiones comerciales de las sociedades del pasado pudiesen ser a su vez, aprehendidas con el vocabulario y los conceptos de la nueva sociedad.

25 Se puede apelar a otros ejemplos: la formulación de la teoría psicoanalítica es inseparable de las transformaciones en los comportamientos sexuales, en las relaciones parentales, en las concepciones de la infancia, etc. De igual modo, las formulaciones de Marx acerca de la alienación del trabajo y las diversas elaboraciones del marxismo acerca de la clase y de la lucha de clases, son ineludiblemente prácticas en la lucha social y en la formación misma de la clase; así como las exégesis e interpretaciones diversas de su obra, están en la trama de la lucha político-ideológica por su representación (es decir, por su constitución).

26 Por ejemplo, la apelación a la ciudadanía pudo convertirseen la lucha política e ideológica-en enmascaramiento de la desigualdad o en referencia en la demanda de igualdad. Es decir, la misma noción, la misma categoría, acciona significativamente diferente, aún con sentidos opuestos, en esquemas diferentes de representación del mundo, que existen en competencia o en lucha y oposición y que tienen que ver con el poder (de nominar, de instituir, de estructurar).

27 Me refiero a la 'crítica a la crítica' neoliberal, sea aquella a la que le subyace una visión romántica del bienestar, o la que ve en toda política social una herramienta de dominación o un recurso del clientelismo político.

\section{Estela Grassi}

Doctora en Antropología Social

Licenciada en Trabajo Social y en Antropología

Profesora Titular Regular e Investigadora de la Facultad de Ciencias Sociales de la Universidad de Buenos Aires (UBA)

Marcelo T. de Alvear, 2230

(1122) Ciudad de Buenos Aires - Argentina 